\title{
Examination of Athletes' Anxiety, Motivation, Imagination Value in Competitions with Different Severity Level
}

\author{
Mustafa SALLAYICI ${ }^{1}$ \\ İpek EROĞLU KOLAYİS ${ }^{2}$ \\ İnci KESILLMIŞ ${ }^{3}$ æ \\ Mehmet Melih KESILMIŞ̧ ${ }^{4}$
}

${ }^{s, 4}$ Mersin University, School of Physical Education and Sports, Mersin, Turkey

IEmail: mstfsllyc@gmail.com Tel: +905382243223

Email: incikesilmis@mersin.edu.tr.Tel:+9032+3610463

${ }^{4}$ Email: ruimelih@hotmail.com Tel: +903243610463

${ }^{2}$ Sakarya University, School of Physical Education and Sports, Sakarya, Turkey

2Email: ikolavis@sakarya.edu.tr Tel: +9053227324t4

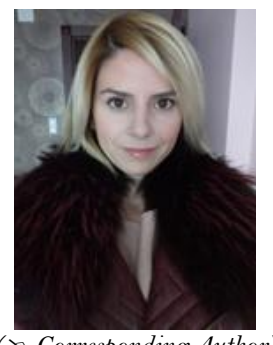

\begin{abstract}
The objective of this study was to examine athletes' anxiety, motivation and imagination value in competitions with different severity level. The research was conducted on swimming athlete in elite level 18 female and 19 male totally 37. To measure the level of imagination, imagine inventory in sports and to measure trait anxiety levels STAI were used. For statistical analyses of parametric data, to see the difference between the groups independent groups t-test and for the non-parametric data Mann Whitney-U analyses were used. The level of significance accepted as $\mathrm{p}<0.05$. National team athletes and athletes that participate in $13^{\text {th }}$ European Short Course Swimming Championships and Turkey National Team Selection, before the day of the event selection and on the morning of the competition the difference between the cognitive anxiety levels, somatic anxiety levels and confidence levels was not statistically significant ( $p>0.05)$. Athletes that participate in 13th European Short Course Swimming Championships and Turkish national team athletes before the day of the event selection and on the morning of the competition while cognitive anxiety and self-confidence levels were statistically different $(p<0.05)$, the difference between somatic anxiety levels was not statistically significant $(p>0.05)$. The athletes that selected and non-selected for national team before the day of the event selection and on the morning of the competition the difference between the cognitive anxiety levels, somatic anxiety levels, confidence levels, motivation and imagination levels was not statistically different $(p>0.05)$.
\end{abstract}

Keywords: Anxiety, Swimming, Motivation, Imagination.

Citation | Mustafa SALLAYICI; İpek EROĞLU KOLAYIS. İnci KESILMIS; Mehmet Melih KESILMIS (2018). Examination of Athletes' Anxiety, Motivation, Imagination Value in Competitions with Different Severity Level. Asian Journal of Education and Training, 4(1): 9-12.

History:

Received: 14 December 2017

Revised: 5 January 2018

Accepted: 10 January 2018

Published: 15 January 2018

Licensed: This work is licensed under a Creative Common

Attribution 3.0 License (c))

Publisher: Asian Online Journal Publishing Group
Contribution/Acknowledgement: All authors contributed to the conception and design of the study.

Funding: This study received no specific financial support.

Competing Interests: The authors declare that they have no conflict of interests.

Transparency: The authors confirm that the manuscript is an honest, accurate, and transparent account of the study was reported; that no vital features of the study have been omitted; and that any discrepancies from the study as planned have been explained.

Ethical: This study follows all ethical practices during writing.

\section{Contents}

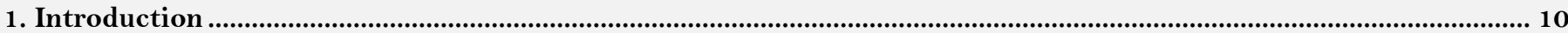

2. Methods

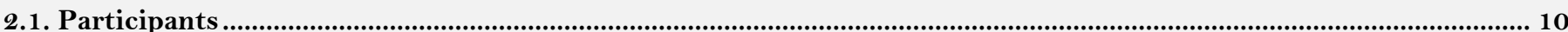

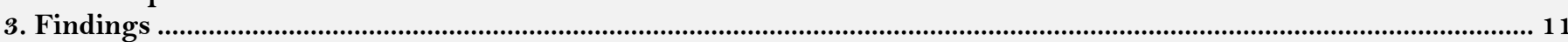

4. Discussions a.

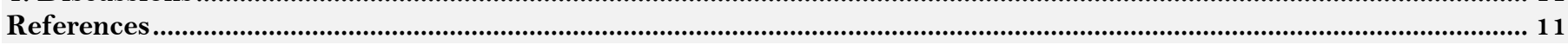




\section{Introduction}

Individuals in sporting activities are faced with both physical and psychological overloads. In order to minimize the impact of these overloads, training is being done against the factors that cause it to be. However, training programs often focuses on technical and tactical training with the conditioning work, and the psychological conditions of achieving success on the sport are often neglected (İkizler and Karagözoglu, 1997). Recent researches show that sporting success is not only depends on biomechanical factors, but also on psychological factors such as anxiety, stress, and motivation (Konter, 1996). Tallis (2003) reported that; lack of control over the repetitive thoughts and the tendency to think that things will get worse are shown among the characteristics of the anxiety (Tallis, 2003). There are two different types of anxiety. But, there is an anxiety process on the basis of both types of anxiety. The anxiety process includes a series of complex cognition, emotion, physiological, and behavioral activity series. The state and continuity elements can explain more clearly the multifaceted anxiety (Aşçı and Gökmen, 1995). Independent of the environmental conditions of the individual as restlessness, pessimism, extreme sensitivity and intense reactions under stress can be defined as constant anxiety (Kuru, 2000). State anxiety arises when a dangerous, unwanted situation is encountered (Spielberger et al., 1983). It shows physiological parameters that develop directly, without autonomic stimulation and have an effect on anxiety. Somatic anxiety can manifest itself in reactive reactions such as rapid heart rate, short and intermittent breathing, moist hands, abdominal pain and tense muscles (Konter, 1996). Unlike somatic anxiety, cognitive anxiety refers to negative thoughts and anticipations, impaired attention, no concentration, negative thoughts about one's own self (Weinberg and Gould, 1995). Motivation is to act for intentional behavior toward a specific target with internal pushing forces. Motivation is all the factors that lead people to certain behaviors in certain situations (Güney, 2000). Imagination is to live it, to consume energy while it revives an event in your mind (Tiryaki, 2000). Getting in the first place is the most attractive motivation for the athletes. The game is a source of motivation for beginners. Turkey, Balkan, Europe, World, Olympic competitions are a great source of motivation for young swimmers. From today's technology, all the clubs are now able to benefit from the same extent in the swimming sector. It is thought that psychological factors affect the grades of swimmers who have the same materials as well as factors such as training, nutrition, athlete's age and so on. Therefore, in this study, differences in psychological factors such as anxiety, imagination, motivation, and performance effects were investigated according to the degree of importance of competition.

\section{Methods}

\subsection{Participants}

The universe of this research was composed of elite level sportsmen who were dealing with the swimming branch in İstanbul, Kocaeli, Ankara, Kastamonu, Bursa. This research was conducted on 18 female and 19 male athletes in the $13^{\text {th }}$ European Short Course Championships selection tournament and $13^{\text {th }}$ European Short Course Championship.

\subsection{Data Collection Materials}

In this study, sports imagination inventory was used to measure imagination levels of swimmers and State Trait Anxiety Inventory was used to measure levels of trait anxiety.

\subsubsection{S.T.A.I (State Trait Anxiety Inventory)}

State Trait Anxiety Inventory is the Spielberger State and Trait Inventory that translated to Turkish by Öner and Compte (1985) and reliability studies were carried out by Öner (1977). Inventory was developed by Spielberger et al. (1970) and has two subdivisions. These sections measure two different state of anxiety as state and trait. State Trait Anxiety Inventory consists of 20 questions. In the trait anxiety section, materials often require individuals to describe themselves according to how they feel. In the state anxiety section, there are questions about how they feel at that moment. The emotions and behaviors expressed in the anxiety items are evaluated as (1) almost never (2) sometimes (3) very time (4) almost always according to the frequency of individuals living. The emotions and behaviors expressed in the items of the state anxiety scale are answered by marking one of them as (1) no (2) a little (3) very (4) according to the degree of violence of these kinds of experiences. Test-repeat-test reliability, criterion and structure validity of the inventory are high. The reliability coefficients obtained by the test-repeat-test technique ranged from 0.73 to 0.86 for trait anxiety scale and from 0.16 to 0.54 for state anxiety scale. The fact that the reliability coefficients of the state anxiety scale are low suggests that such anxiety is transient and depending on the situation, state anxiety is completely consistent. However, it has been found that the alpha correlation coefficients, reflecting the reliability, stability and internal consistency of this scale more appropriately, are between 0.83 and 0.92 and have a high internal consistency (Sivrikaya, 1998).

\subsubsection{Imagination Inventory in Sports}

Hall et al. (1998) have developed the Sport Imagery Questionnaire (SIE) in order to determine which type of imagine athletes use. A total of 337 athletes, 188 males and 149 females, aged between 15 and 36 ages in 7 sports branches (athletics, basketball, fencing, football, tennis, volleyball, swimming) participated in the adaptation of the spore imaging inventory for Turkish athletes. The original inventory consists of 5 sub-dimensions (Cognitive General Intelligence, Cognitive Specialization, Motivational-General Awareness, Motivational-General Mastery, Motivational Specialization) and 30 items. Factor analysis was used to test construct validity of the inventory. Four factors explained approximately $51 \%$ of the variance. Turkish athletes did not encounter the dimension of Cognitive Specialization. Other dimensions are 'Cognitive Imaging', 'Motivational Specialization', 'MotivationalGeneral Alert' and 'Motivational-General Mastery'. The internal consistency values calculated with Cronbach Alpha were found to be .81 for the "Cognitive Imaging" sub-dimension, .80 for the "Motivational Special" subdimension, .71 for the "Motivational General Alertness" sub-dimension and .59 for the "Motivational General Alertness". For the test-repeat-test reliability, the reliability of the inventory for 36 athletes with 3-week intervals 
is .74 for "Cognitive Imagination", .91 for "Motivational Special Implication", .91 for "Motivational General Alertness .88", and .90 for "Motivational General Mastership".

\subsection{Statistical Analyses}

The data obtained from the study were evaluated with the Graph Pad Prism 5 Demo.

In the statistical analysis of the data, the mean and standard deviation values were examined. The Independent Samples t-test was used to look for the difference between the groups that met the parametric assumptions and the Mann Whitney-U Test was used for the non-parametric tests. The significance level was taken as $\mathrm{p}<0.05$.

\section{Findings}

The research was conducted on 37 athletes participating in the $13^{\text {th }}$ European Short Course Swimming Championship Turkish National Team Selection and the $13^{\text {th }}$ European Short Course Swimming Championship in 2009.

18 of them are female and 19 of them are male. The average age of the national team athletes dealing with swimming was $\mathrm{x}=19,28 \pm 2,653$. The ages of selected athletes for national team were found to be $\mathrm{x}=11,39 \pm$ 3,320 . The average age of the athletes who were not selected as national athletes was found as $\mathrm{x}=18,37 \pm 2,650$. The age of the sportsmen who can not enter the national team is $\mathrm{x}=10.32 \pm 2.689$.

Table-1. Statistically significant difference was found between the athletes participating in the 13th European Short Course Swimming Championship and the cognitive anxiety levels of the morning of competition and 1 day before the competition.

\begin{tabular}{l|l|l|l|l|l}
\hline & $\mathbf{N}$ & $\mathbf{X}$ & $\mathbf{S}$ & $\mathbf{t}$ & $\mathbf{p}$ \\
\cline { 1 - 5 } The Day Before the Competition & 18 & 28,17 & 5,783 & \multirow{2}{*}{3,465} & \multirow{2}{*}{$0,003^{*}$} \\
\hline Competition Morning & 18 & 26,44 & 5,690 & & \\
\hline
\end{tabular}

Source: Mustafa Sallayıcı

Table-2. Statistically significant difference was found between the athletes of the Turkish National Team participating in the 13th European Short Course Swimming Championship 1 day before the competition and their confidence levels in the competition morning

\begin{tabular}{l|l|l|l|l|l}
\hline & N & X & S & t & p \\
\cline { 1 - 4 } The Day Before the Competition & 18 & 18,50 & 4,190 & \multirow{2}{*}{2,474} & \multirow{2}{*}{$0,024^{*}$} \\
\hline Competition Morning & 18 & 19,78 & 4,413 & \\
\hline
\end{tabular}

Source: Mustafa Sallayıcı

The difference between the levels of cognitive anxiety, somatic anxiety, self-confidence, motivation and imagination was not statistically significant $(p>0.05)$ the day before the competition to selected and not selected athletes.

\section{Discussions}

There was no significant difference according to the age variable in terms of state and trait anxiety scores of the athletes. In the literature review, studies supporting our research findings were also found. Özbekçi (1989) did not find a relationship between basketball, volleyball and athletes in terms of state anxiety scores and age and competition stress levels. In another study, Arseven and Güven (1992) analyzed the data related to the level of anxiety of the athletes in various fields (basketball, handball, volleyball and athletics) divided into two groups according to their ages (over 20 years old and under 20 years old) and they have not found a relationship Although these results support the study, it should be considered that considering the presence of some counter-measures should increase the number of such studies. A statistically significant difference was found between the athletic athletes participating in the $13^{\text {th }}$ European Short Course Swimming Championship and the cognitive anxiety levels of the morning of competition and the morning of the competition. Another finding that supports this finding is seen in studies conducted by Çoksevim et al. (2008). In this study, the state and continuity anxiety scores before and after the Turkey Kickboxing Championship were examined and it was seen that pre-competition anxiety scores were significantly higher. This may be the result of cognitive considerations such as the excitement and pride of being an elite athlete, a strong concentration, having a significant degree and championship, which is a major stressor for pre-competition sportsmen. A statistically significant difference was found according to the importance of the sports branch and the competition in terms of the state of the athletes and the state of continuous anxiety. According to the findings, there is no significant difference in the pre-competition state anxiety level scores between individual sports and team sports. However, the average of team sports groups was significantly lower than that of individual sports groups. This result is supported by Özbekçi (1989)'s study that athletes reached to the result that their competition environment stressed more according to team sports.

However, the results of the study contradict the findings of Aktop and Erman (2002) which compare the level of trait anxiety of team and individual athletes. When these results are examined; the high level of state anxiety scores of the athletes in individual sports may be due to the fact that the athletes' responsibility for the competition alone may vary and depend on the importance of the competition. In addition, the anxiety that the trainings will be wasted in case of failure may have increased the state anxiety. The fact that athletes have a small number of competitions at the national team level can raise state anxiety for later successes. However, it should also be considered that the high level of state anxiety in individual athletes may be an advantage in coping with persistent anxiety through good control and analysis.

\section{References}

Aktop, A. and K.A. Erman, 2002. Comparison of achievement motivation, self-esteem and trait anxiety levels of team and individual athletes. 7 th International Sport Sciences Congress, Antalya.

Arseven, A. and Ö. Güven, 1992. Anxiety levels of the athletes in the competition environment. 2nd National Sport Sciences Congress, Ankara: Hacettepe University. 
Aşçı, F.H. and H. Gökmen, 1995. The relationship among competition anxiety success, sport experience and athletic competence in female handball players. Hacettepe Sport Sciences Journal, 6(2): 38-47.

Çoksevim, B., N. Sarıtaş, M. KAYA and O. Pepe, 2008. Continuity, short symptom inventory findings before and after the match status in Kick Boxers. Türkiye Kick Boks Federasyonu Spor Bilimleri Dergisi, 1(1): 22-27.

Güney, S., 2000. Behavioral sciences. Ankara: Nobel.

Hall, C.R., D.E. Mack, A. Paivio and H.A. Hausenblas, 1998. Imagery use by athletes: Development of the sport imagery question naire. International Journal of Sport Psychology, 29(1): 73-89. View at Google Scholar

İkizler, C. and C. Karagözoglu, 1997. Sporda başarının psikolojisi. İstanbul: Alfa Basım Yayım Dagıtım.

Konter, E., 1996. Sports psychology and football. Izmir: Saray Medical Publications.

Kuru, E., 2000. Psychology in sports. Ankara: Gazi University Iletisim Faculty Printery.

Öner, N., 1977. State trait anxiety inventory validity in Turkish society. Unpublished Associate Professor Thesis. Ankara: Hacettepe University, Department of Psychology.

Öner, N. and A.L. Compte, 1985. Handbook of state trait anxiety inventory. Istanbul: Bogaziçi University Publications.

Özbekçi, F., 1989. Investigation of competition stress levels experienced in different sports branches. Unpublished Master Thesis. Marmara University, Social Sciences Institute, İstanbul.

Sivrikaya, K., 1998. Analysis of physical characteristics, anxiety level and match performance of male and female handball players at different age categories. Gazi University, Institute of Health Sciences. Doctoral Thesis, Ankara.

Spielberger, C.D., R.L. Gorsuch and R.R.E. Cushene, 1970. Manual for the state-trait anxiety inventory. Palo Alto, CA: Consulting Psychologists Press.

Spielberger, C.D., R.L. Gorsuch, R. Lushene, P.R. Vagg and G.A. Jacobs, 1983. Manual for the state-trait anxiety inventory. Palo Alto, CA: Consulting Psychologists Press.

Tallis, E., 2003. Overcoming concerns. İstanbul: Sistem Publications.

Tiryaki, S., 2000. Sport psychology concepts theories and practice. Eylül Kitap.

Weinberg, R.S. and D. Gould, 1995. Arousal, stress, and anxiety. In R. S. Weinberg \& D. Gould (Eds.), Foundations of sport and exercise psychology. Champaign, IL: Human Kinetics. pp. $91-113$. 